\title{
Small Molecule Glycomimetics Inhibit Vascular Calcification via c-Met/Notch3/ HES1 Signalling
}

\author{
Ayman M. Mahmouda, ${ }^{a, b}$ Alan M. Jones ${ }^{d}$ Gary P. Sidgwick ${ }^{a}$ Ayman M. Arafat \\ M. Yvonne Alexandera Fiona L. Wilkinson ${ }^{a}$ \\ ${ }^{a}$ Cardiovascular Science Group, Centre for Bioscience, Department of Life Sciences, Manchester \\ Metropolitan University, Manchester, UK, 'bPhysiology Division, Department of Zoology, Faculty of \\ Science, Beni-Suef University, Beni-Suef, Egypt, 'Department of Endocrinology, Diabetes and Nutrition, \\ Center for Cardiovascular Research (CCR), Charité-University Medicine Berlin, Berlin, Germany, 'School \\ of Pharmacy, University of Birmingham, Edgbaston, UK
}

\section{Key Words}

Calcification • Glycomimetics • BMP-2 • Alkaline phosphatase • Osteogenic signalling

\begin{abstract}
Background/Aims: Vascular calcification represents a huge clinical problem contributing to adverse cardiovascular events, with no effective treatment currently available. Upregulation of hepatocyte growth factor has been linked with vascular calcification, and thus, represent a potential target in the development of a novel therapeutic strategy. Glycomimetics have been shown to interrupt HGF-receptor signalling, therefore this study investigated the effect of novel glycomimetics on osteogenic signalling and vascular calcification in vitro. Methods: Primary human vascular smooth muscle cells (HVSMCs) were induced by $\beta$-glycerophosphate $(\beta-G P)$ and treated with 4 glycomimetic compounds (C1-C4). The effect of $\beta$-GP and C1-C4 on alkaline phosphatase (ALP), osteogenic markers and c-Met/Notch3/HES1 signalling was determined using colorimetric assays, qRT-PCR and western blotting respectively. Results: C1-C4 significantly attenuated $\beta$-GP-induced calcification, as shown by Alizarin Red S staining and calcium content by day 14. In addition, C1-C4 reduced ALP activity and prevented upregulation of the osteogenic markers, BMP-2, Runx2, Msx2 and OPN. Furthermore, $\beta$-GP increased c-Met phosphorylation at day 21, an effect ameliorated by C2 and C4 and the c-Met inhibitor, crizotinib. We next interrogated the effects of the Notch inhibitor DAPT and confirmed an inhibition of $\beta$-GP up-regulated Notch3 protein by C2, DAPT and crizotinib compared to controls. Hes- 1 protein upregulation by $\beta-G P$, was also significantly downregulated by $C 2$ and DAPT. GOLD docking analysis identified a potential binding interaction of C1-C4 to HGF which will be investigated further. Conclusion: These findings demonstrate that glycomimetics have potent anti-calcification properties acting via HGF/c-Met and Notch signalling.




\section{Cellular Physiology Cell Physiol Biochem 2019;53:323-336 \\ \begin{tabular}{ll|l} 
DOl: 10.33594/000000141 & $\begin{array}{l}\text { O } 2019 \text { The Author(s). Published by } \\
\text { Cell Physiol Biochem Press GmbH\&Co. KG }\end{array}$
\end{tabular} \\ Mahmoud et al.: Glycomimetics Prevent Vascular Calcification}

\section{Introduction}

Vascular calcification is an active and highly regulated process of abnormal mineralisation of the vessel wall and is a key risk factor for adverse cardiovascular events [1]. There is a particularly high prevalence of vascular calcification in patients with diabetes and chronic kidney disease (CKD) [2, 3]. When vascular calcification is localised to atherosclerotic plaques, it occurs as microcalcifications, which could represent an early stage of the process, that may progress to larger calcified blocks [4-6].

Bone morphogenetic protein-2 (BMP-2) and other bone matrix proteins, including osteocalcin, osteopontin (OPN) and osteonectin have been identified within the vicinity of vascular calcification [7]. BMP-2 is a member of the transforming growth factor- $\beta$ superfamily [8] associated with osteoblast differentiation and bone formation [7]. Reports suggest the effects of BMP- 2 are executed by upregulating Runt-related transcription factor- 2 (Runx2) [9] and alkaline phosphatase (ALP) expression and activity [10]. Runx2 is a master transcription factor that plays an essential role in osteoblast differentiation, regulating gene expression of bone matrix proteins and proteins important for bone mineralization [11]. Indeed, Runx2 knockdown has been shown to block bone formation and induce neonatal lethality in mice [12-14], whereas overexpression in vascular smooth muscle cells (VSMCs) induced a marked osteo-/chondrogenic phenotype [15]. Furthermore, overt calcification in diabetes and/or atherosclerosis was found to be preceded by Runx2 expression in the vasculature $[16,17]$, highlighting its role in vascular mineralisation and calcification.

Hepatocyte growth factor (HGF), a mesenchyme-derived cytokine with multiple biological effects, is a high affinity ligand for the c-Met receptor [18]. Elevated systemic levels and increased tissue expression of HGF and its receptor c-Met have been related to the progression of atherosclerosis and plaque development respectively [19, 20]. HGF/cMet signalling is known to promote osteogenic differentiation of bone marrow stromal cells [21] and previous studies from our group show that under specific micro-environmental conditions, such as hypercalcemia or hyperphosphatemia, HGF over-expression accelerates calcification in human VSMCs in vitro, via an up-regulation of osteogenic proteins, namely Runx2, ALP, Osteocalcin (OC), BMP2, and Osterix, an effect which can be blocked by inhibition of endogenous HGF/c-Met signalling [18]. In addition, we have demonstrated HGF/c-Met binding increased Akt phosphorylation, activation of Notch and its downstream target protein HES1, where the calcification process was subsequently attenuated in the presence of the Notch inhibitor DAPT, leading us to suggest that Notch/Hes1 signalling is essential for HGF-induced VSMC osteogenic differentiation [18].

Notch is a key signalling pathway in the physiological differentiation and cross-talk between different types of cells. Notch receptors (Notch1-4) and ligands are expressed in the vascular system, and activation of these receptors results in the release of Notch intracellular domain (NICD) which translocate to the nucleus where it regulates several target genes, including HES1 [22]. Notch3 influences the phenotype and functions of VSMCs [23] and since we have demonstrated the activation of c-Met/Akt/Notch3 signalling in the osteogenic differentiation of VSMCs [18], we have proposed that c-Met signalling could represent a target in the prevention and/or treatment of vascular calcification, via activation of Akt and Notch3 signalling in vitro.

Glycosaminoglycans (GAGs) are components of the extracellular matrix and act as mediators of cellular signalling. Heparan sulfate (HS) is a highly sulfated GAG present in the extracellular matrix of almost all tissues, and is known to be critically implicated in regulating angiogenesis, inflammation, immunity and metastasis [24-26]. The biological effects of HS are known to be mediated by the variable sulfation pattern [27], thus HS oligosaccharides can mimic the former cellular processes in biological systems, and help overcome the complexity of the synthesis of HS mimetics $[28,29]$. It has also been shown that HS mimics can inhibit HGF/c-Met interaction [30] and we recently established for the first time, the protective effect of a class of small molecule glycomimetics against endothelial dysfunction in vitro and ex vivo [31]. 


\section{Cellular Physiology Cell Physiol Biochem 2019;53:323-336

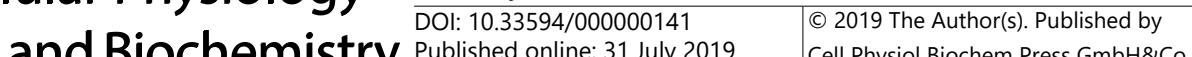 and Biochemistry Published online: 31 July 2019 Cell Physiol Biochem Press GmbH\&Co. KG \\ Mahmoud et al.: Glycomimetics Prevent Vascular Calcification}

Since endothelial dysfunction plays a key role in the pathogenesis of vascular disease, including the development of atherosclerotic plaque and vascular calcification, and the predicted ability of glycomimetics to interrupt HGF/c-Met signalling, the aim of the study was to evaluate whether small molecule glycomimetics inhibit vascular calcification in an in vitro human VSMC model. To the best of our knowledge, studies on the potential of small molecule HS mimetics in the protection against VSMC calcification have not yet been studied.

\section{Materials and Methods}

\section{Explanting and culture of human VSMCS}

VSMCs were obtained by tissue explantation using human popliteal arterial sections as previously described [32]. The tissue samples were collected from patients with peripheral vascular disease following below knee amputation, with informed consent and full ethical approval from the NRES Committee North West-Lancaster (REC reference; 14/NW/1062). After cleaning, the adventitia was removed and medial tissue was dissected into $1 \mathrm{~mm}$ squares and incubated in smooth muscle cell growth medium (Cat. No. C-22162; PromoCell GmbH, Heidelberg, Germany). The medium was changed every 2 days and human VSMCs were used between passages 2 and 4 .

\section{Induction of calcification and treatments}

$\beta$-glycerophosphate ( $\beta$-GP) has been reported to induce calcification in cultured VSMCs [33] and is commonly utilised in a well-established in vitro model of vascular calcification for functional and mechanistic studies. In the present study, VSMCs were cultured in the regular growth media (PromoCell $\mathrm{GmbH}$, Heidelberg, Germany). At $80 \%$ confluence, the cells were switched to DMEM containing $10 \%$ fetal bovine serum, $100 \mathrm{U} / \mathrm{ml}$ penicillin, $100 \mathrm{mg} / \mathrm{ml}$ streptomycin, $2.6 \mathrm{mM} \mathrm{CaCl}_{2}$ and $5 \mathrm{mM} \beta$-GP, to induce mineralization. Starting from the first day of induction, $10 \mu \mathrm{M}$ of each test compound was added and the media was changed every 3 days.

\section{Alizarin red staining}

At day 21, VSMCs in 6-well plates were washed 3 times with PBS and fixed in 4\% formaldehyde for 10 minutes. After washing, the cells were incubated with $2 \%$, wt/vol alizarin red S (pH 4.2), as previously described $[18,32,34]$. The stain was eluted by incubation with $10 \%$ formic acid (1ml/well) with shaking for 5 minutes and transferred to a 96 -well plate where the absorbance was read at $414 \mathrm{~nm}$ on a microplate reader (BioTek). 10\% formic acid was used as a blank.

\section{Calcium deposition quantification}

VSMCs were seeded into 12-well plates and were incubated in osteogenic medium with and without the glycomimetics C1-C4 for 14 days. The cells were washed with cold PBS and the calcium was eluted with $0.6 \mathrm{M} \mathrm{HCl}$ for $24 \mathrm{~h}$. The calcium content in the supernatant was then determined colorimetrically using a reagent kit purchased from Abcam (Cat No. ab102505) where the free $\mathrm{Ca}^{2+}$ forms a chromogenic complex with 0-cresolphthalein. The optical density of the chromogen was measured at $575 \mathrm{~nm}$ on a microplate reader (BioTek) and the data were normalized to total protein content, as determined using a bicinchoninic acid (BCA) protein assay (Pierce Biotechnology).

\section{Alkaline Phosphatase (ALP) Assay}

To test the effect of small molecule glycomimetics on ALP activity, VSMCs were cultured in 12-well plates with osteogenic medium and treated with $10 \mu \mathrm{M}$ C1-C4. At days 4, 7 and 10, the cells were washed with PBS and lysed with 1\% Triton X-100 in PBS. The lysate was centrifuged and total cellular proteins were quantified. Twenty $\mu$ g protein was used to assay ALP activity as previously described [34]. The results were normalized to total protein and an enzyme unit is the number of nmol of nitrophenol formed per $\mu \mathrm{g}$ of cellular protein per minute. 
Cell Physiol Biochem 2019;53:323-336

\begin{tabular}{l|l}
\hline DOI: $10.33594 / 000000141$ & (c) 2019 The Author(s). Published by \\
\hline
\end{tabular}

Mahmoud et al.: Glycomimetics Prevent Vascular Calcification

Quantitative real-time $P C R$ (qRT-PCR)

On day 7, cells in 6-well plates were harvested for isolation of RNA using Trizol reagent (Invitrogen). RNA was quantified and reverse transcribed into cDNA using SuperScript II reverse transcriptase and oligo deoxythymidine primers (Sigma) on Surecycler 8800 thermocycler (Agilent Technologies). The first strand

Table 1. Primers used for qRT-PCR

\begin{tabular}{lcc}
\hline Gene & Sequence (5'->3') & GenBank accession number \\
\hline \multirow{2}{*}{ BMB2 } & F: GGGTGGGGGAAAGGTAATGAA & \multirow{2}{*}{ AF040249.1 } \\
& R: CACCGTTGCCTCTGTTGCAT & \\
CBFA1 & F: CCACCGAGACCAACAGAGTC & NM_001015051.3 \\
& R: TCACTGTGCTGAAGAGGCTG & \\
MSX2 & F: CTCTCCACGAAGGCAGTACC & NM_002449.4 \\
& R: GCCTCCGCCTACAGAACAAA & \\
OPN & F: AGCATACTTCCTTGGCCTGA & L09555.1 \\
& R:TCAGTGAGAGTTGAATTTAGGTGT & \\
ALP & F: GGCTCCAGGGATAAAGCAGG & XM_006710546.1 \\
& R: GCATACCTGGCACTAAGGAGT & \\
GAPDH & F: GGAGCGAGATCCCTCCAAAAT & NM_001256799 \\
& R: GGCTGTTGTCATACTTCTCATGG & \\
\hline
\end{tabular}
cDNA was amplified using SYBR Green master mix (Bioline, UK) in a total volume of $20 \mu \mathrm{L}$ with the primer sets outlined in Table 1 . The samples were amplified for 40 cycles with a denaturation at $95^{\circ} \mathrm{C}$ for $30 \mathrm{sec}$, annealing for $60 \mathrm{sec}$ and extension for $30 \mathrm{sec}$ at $72{ }^{\circ} \mathrm{C}$. Melting curves and agarose gel electrophoresis were used to assess quality of the PCR products. The results were analysed using the $2^{-\Delta \Delta \mathrm{Ct}}$ method and data normalized to GAPDH.

\section{Western blot analysis}

Western blot analysis was used to determine the effects of glycomimetics and inhibitors of Notch and c-Met on c-Met phosphorylation, as well as Notch3 and HES1 protein levels in VSMCs. Cells were cultured in osteogenic medium with and without $10 \mu \mathrm{M}$ C2, $10 \mu \mathrm{M} \mathrm{C} 4,1 \mu \mathrm{M}$ DAPT (N-[N-(3, 5-Difluorophenacetyl$L$-alanyl)]-S-phenylglycine ${ }^{t}$-butyl ester; Sigma-D5942), or $1 \mu \mathrm{M}$ crizotinib (c-Met inhibitor, Sigma-PZ0191) for 21 days. The cells were harvested and homogenized in RIPA buffer supplemented with proteinase/ phosphatase inhibitors. Total proteins were quantified and samples were separated using 10\% SDSpolyacrylamide gel electrophoresis (SDS/PAGE) and then transferred to PVDF membrane. Blots were blocked and incubated overnight at $4{ }^{\circ} \mathrm{C}$ with rabbit antibodies for phospho-c-Met ${ }^{\text {Tyr1349 }}$ (ab68141), c-Met (sc-161), Notch3 (sc-5593), HES-1 (ab71559), or $\alpha$-tubulin (ab7291). After incubation with the secondary antibodies, the blots were developed with ECL reagent (Amersham Pharmacia Biotech). Protein signals were analysed using ImageJ (version 1.32j, NIH, http://rsb.info.nih/ij/).

\section{Statistical analysis}

Data were analysed using GraphPad Prism 5 (GraphPad Software, San Diego, USA). The results were compared using a one-way analysis of variance (ANOVA) test followed by Tukey's post-hoc analysis. The obtained data were expressed as mean \pm standard error of the mean and P value less than 0.05 was considered significant.

\section{Statement of Ethics}

The tissue samples were collected from patients with full informed consent of the participants and full ethical approval from the NRES Committee North West-Lancaster (REC reference; 14/NW/1062).

\section{Results}

Small molecule glycomimetics inhibit $\beta$-GP-induced calcification in human VSMCs

The effect of small molecule glycomimetics (C1-C4) on $\beta$-GP-induced calcification was evaluated using alizarin red staining (imaging and quantifying the eluted stain), and by calcium assays. Alizarin red staining, performed on day 21, showed that all 4 glycomimetics inhibited $\beta$-GP-induced granular calcified nodule formation (Fig. 1A). This result was validated by measuring the absorbance of the eluted alizarin red stain, with glycomimetictreated VSMCs demonstrating a significant reduction in alizarin red staining compared to 
Fig. 1. Small molecule glycomimetics inhibit $\beta$-GP-induced calcification in human vSMCs. (A \& B) Alizarin red staining showing inhibition of calcification by the small molecule glycomimetics (C1C4) in human VSMC treated with $5 \mathrm{mM}$ $\beta$-GP for 21 days (C) C1-C4 reduce $\beta$-GPinduced calcium deposition at day 14 . Results are mean \pm SEM; $\mathrm{n}=6-8$, and experiments were repeated at least three times independently. $* * * \mathrm{P}<0.001 . \quad \beta-\mathrm{GP}$, $\beta$-glycerophosphate; ns, non-significant.

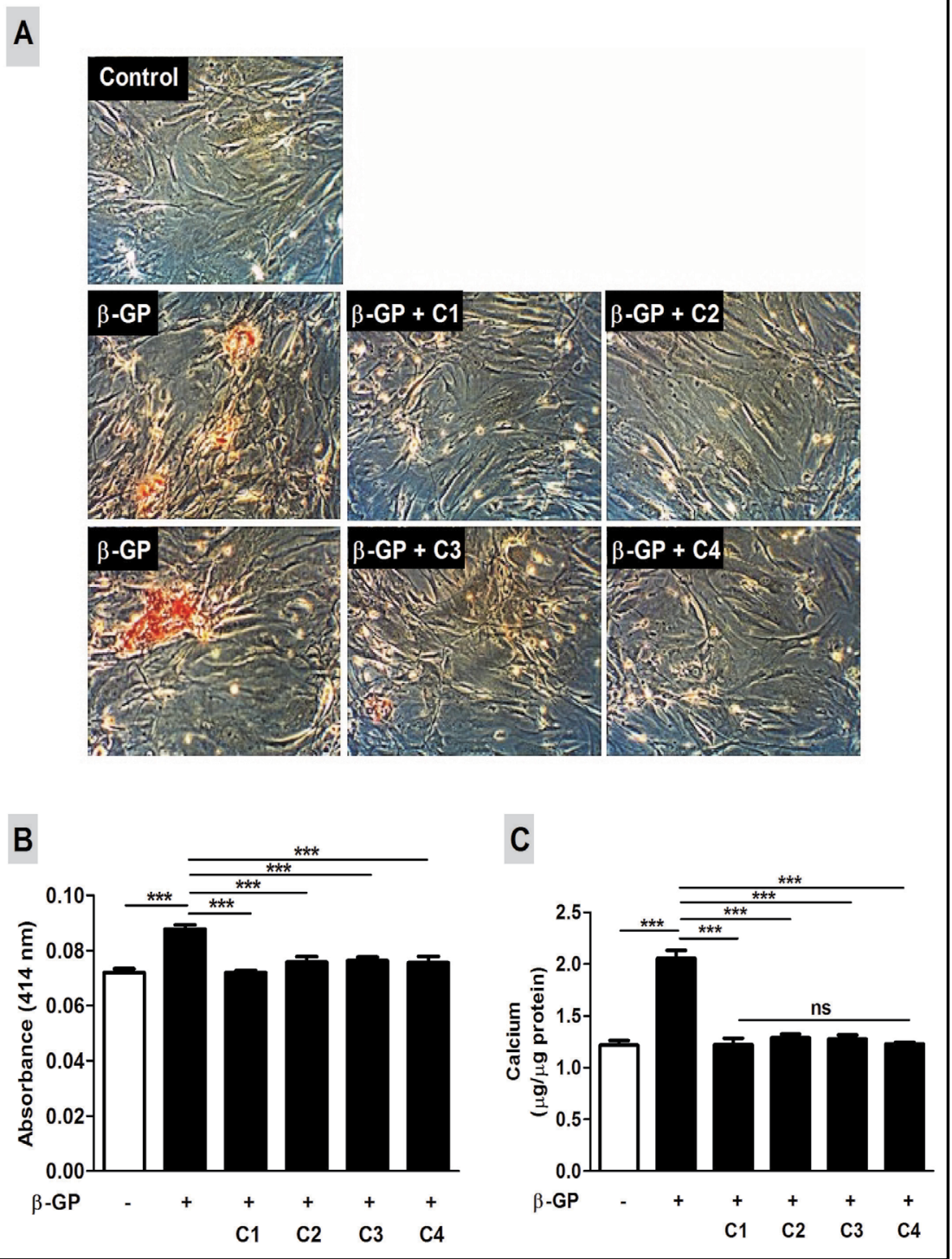

A

B

untreated VSMCs $(\mathrm{P}<0.001)$ to control levels (Fig. 1B). These data were further confirmed using a calcium content assay, where $\beta$-GP treated human VSMCs showed a significant increase in calcium content at day $14(\mathrm{P}<0.001)$, an effect that was significantly decreased to untreated control levels by all tested compounds ( $\mathrm{P}<0.001$; Fig. $1 \mathrm{C})$.

\section{Small molecule glycomimetics prevent $\beta$-GP-induced ALP activity and expression in human} VSMCS

ALP activity and mRNA abundance was measured as an early marker of osteogenic differentiation to further investigate the effect of the glycomimetics on $\beta$-GP-induced calcification. At days 4, 7 and 10, treatment with $\beta$-GP induced a significant increase in ALP activity in human VSMCs $(\mathrm{P}<0.001$; Fig. $2 \mathrm{~A})$. ALP mRNA abundance was significantly up-regulated after 7 days of $\beta$-GP treatment $(P<0.001$; Fig. $2 B)$, which was significantly attenuated $(\mathrm{P}<0.001)$ to untreated control levels after treatment with either $\mathrm{C} 1, \mathrm{C} 2, \mathrm{C} 3$ or $\mathrm{C} 4$. 

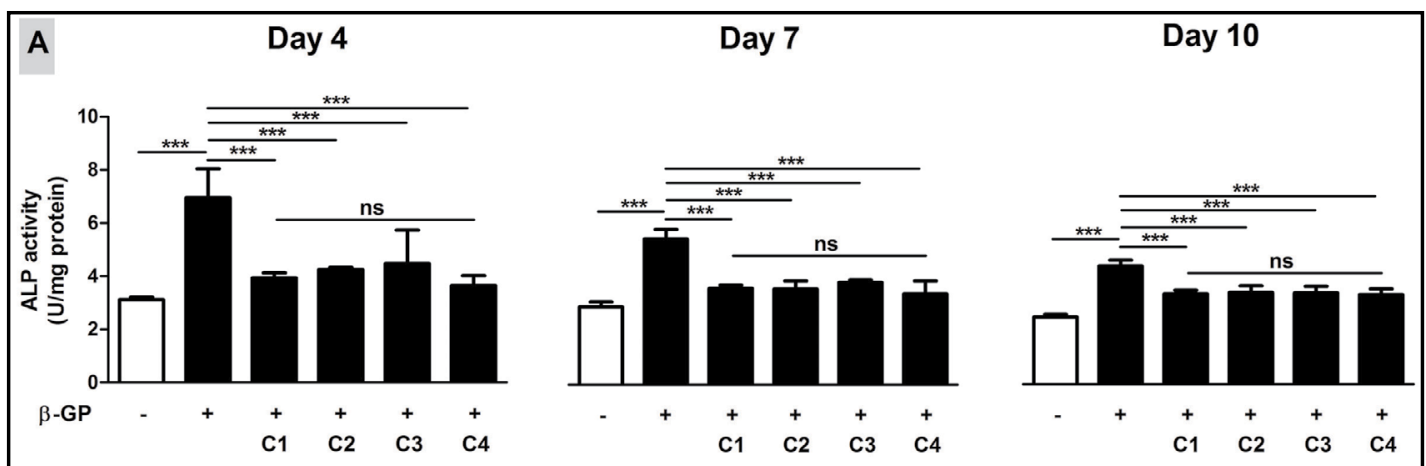

B Day 7

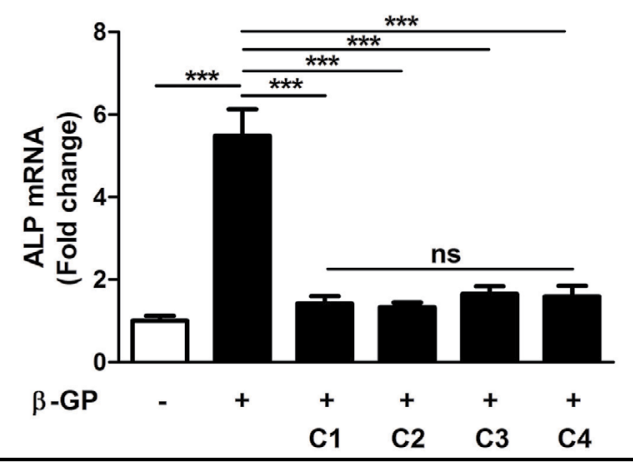

Fig. 2. Small molecule glycomimetics prevent $\beta$-GP-induced ALP activity and mRNA abundance in human VSMCs. (A-C) ALP activity was determined at days 4, 7 and 10. Glycomimetics C1-C4 significantly inhibit $\beta$-GP-induced ALP activity. (D) ALP mRNA abundance was significantly up-regulated after 7 days of $\beta$-GP treatment and was inhibited by C1-C4. Results are mean \pm SEM; $n=6-10$, and experiments were repeated at least three times independently. ${ }^{* * *} \mathrm{P}<0.001 . \beta$-GP, $\beta$-glycerophosphate; ns, non-significant.

Small molecule glycomimetics prevent $\beta$-GP-induced transdifferentiation of human VSMCs into osteoblast-like cells

To assess the effects of the 4 glycomimetics on pathways involved in $\beta$-GP-induced osteogenic differentiation of human VSMCs, the levels of specific mRNAs involved in in this process were investigated. BMP-2, RUNX2 (CBFA1; Core-binding factor $\alpha 1$ ), MSX2 and OPN mRNA abundance were significantly up-regulated in human VSMCs following 7 days of treatment with $\beta$-GP (Fig. 3).

In contrast, glycomimetics $\mathrm{C} 1-\mathrm{C} 4$ significantly reduced the mRNA abundance of $B M P$ $2(\mathrm{P}<0.001), R U N X 2(\mathrm{P}<0.001), M S X 2(\mathrm{P}<0.05)$ and $O P N(\mathrm{P}<0.01)$ compared to the $\beta$-GPinduced cells (Fig. 3). In particular, $\mathrm{C} 1$ and $\mathrm{C} 2$ produced a more marked down-regulation of MSX2 ( $\mathrm{P}<0.01$; Fig. 3C) compared to C3 and C4 $(\mathrm{P}<0.05)$.

Small molecule glycomimetics downregulate c-Met/Notch3/HES1 signalling in $\beta$-GPinduced human VSMCs

Our previous studies have shown that c-Met/Akt/Notch3 signalling is activated during VSMC calcification in vitro [18]. Therefore, we investigated the effect of C1-C4 small molecule glycomimetics on c-Met/Notch3/HES1 regulation after 21 days of $\beta$-GP-induced calcification.

Given that previous data showed no significant differences between all four compounds in terms of osteogenic differentiation, only $\mathrm{C} 2$ and $\mathrm{C} 4$ were selected for further testing. $\beta$-GP significantly increased c-Met ${ }^{\text {Tyr1349 }}$ phosphorylation $(\mathrm{P}<0.01$; Fig. 4A) in human VSMCs at day 21 , whereas it was significantly reduced after the addition of either C2, C4, crizotinib (the c-Met inhibitor) or DAPT (Notch inhibitor) $(\mathrm{P}<0.01)$. 
Fig. 3. Small molecule glycomimetics inhibit $\beta$-GPinduced osteoinductive signalling in human VSMCs. Glycomimetics C1-C4 reduce mRNA abundance of (A) BMP-2, (B) RUNX2, (C) MSX2 and (D) OPN in VSMCs treated with $\beta$-GP for 7 days. Results are mean \pm SEM; $n=6$, and experiments were repeated at least three times independently. $\quad * \mathrm{P}<0.05$, ** $\mathrm{P}<0.01, \quad * * * \mathrm{P}<0.001$. $\beta$-GP, $\beta$-glycerophosphate; ns, non-significant.

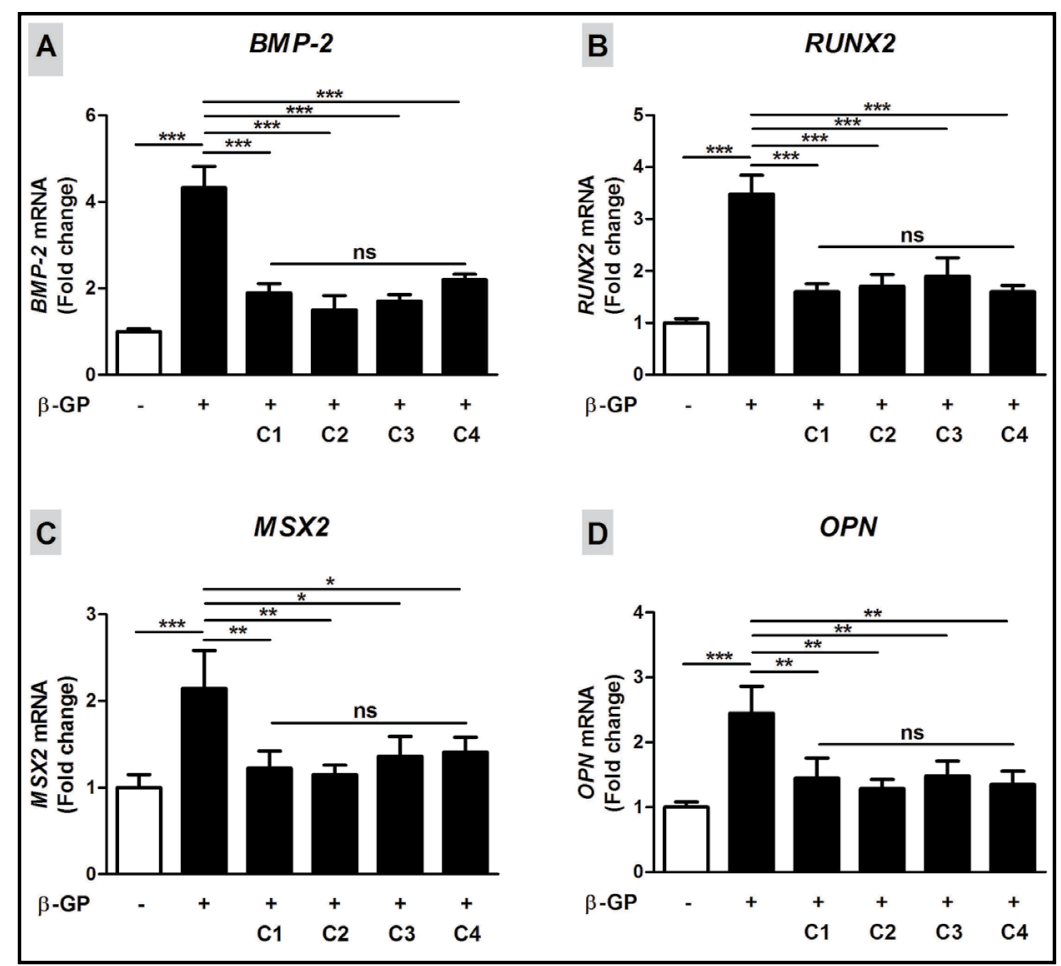

Fig. 4. Small molecule glycomimetics downregulate c-Met/Notch3/ HES1 signalling in $\beta$-GP-induced human VSMCs. (A) c-Met ${ }^{\text {Tyr1349 }}$ phosphorylation was significantly increased after treatment with $\beta$-GP for 21 days which was significantly decreased by $\mathrm{C} 2, \mathrm{C} 4$, crizotinib and DAPT. (B, C) C2 and DAPT significantly decreased Notch3 (B) and HES-1 (C) protein expression in VSMCs treated with $\beta$-GP for 21 days. Results are mean \pm SEM; $\mathrm{n}=6 .{ }^{*} \mathrm{P}<0.05$, ** $\mathrm{P}<0.01, \quad * * * \mathrm{P}<0.001$. $\beta$-GP, $\beta$-glycerophosphate; ns, non-significant.

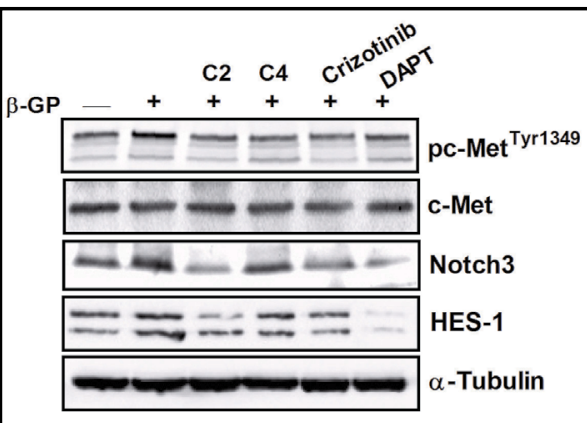

A

B
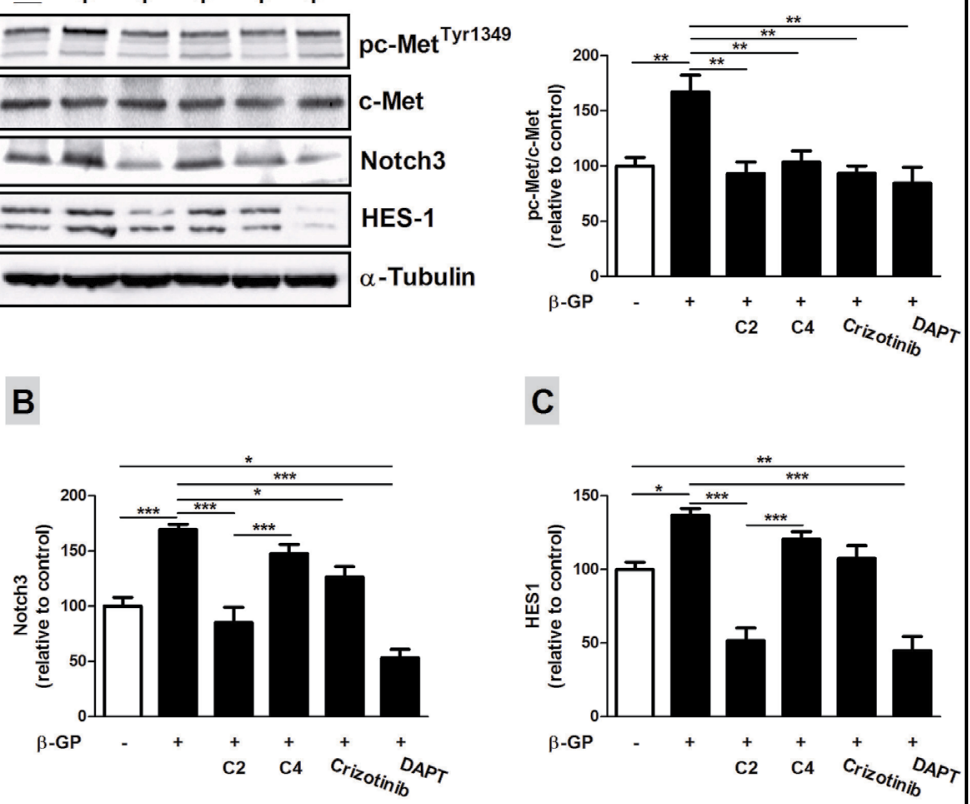

C

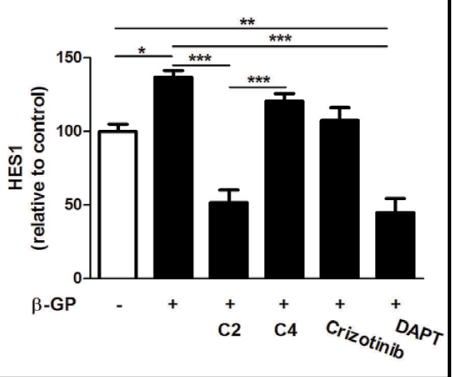

The effect of C2, C4, crizotinib and DAPT on Notch3 levels in $\beta$-GP-induced human VSMCs at day 21 was determined. $\beta$-GP significantly up-regulated Notch3 protein levels $(\mathrm{P}<0.001)$, an effect that was markedly reversed by $\mathrm{C} 2(\mathrm{P}<0.001)$, DAPT $(\mathrm{P}<0.001)$ and crizotinib $(\mathrm{P}<0.05)$, but not with $C 4$ treatment. DAPT significantly inhibited Notch3 expression $(\mathrm{P}<0.05)$ when compared with untreated control cells (Fig. 4B), supporting our previously published data [18]. 


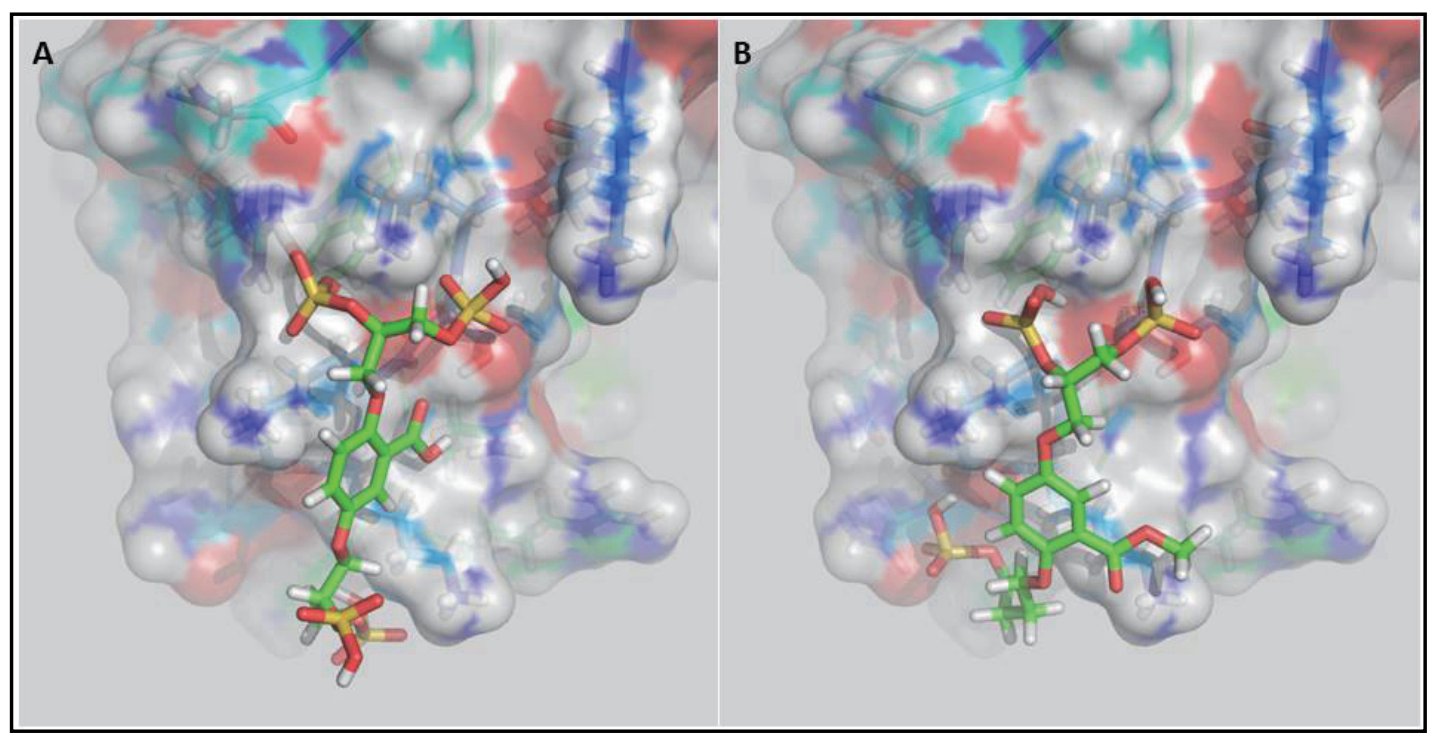

Fig. 5. Representative docking pictures of glycomimetic (A) C2 and (B) C4 in the HGF-heparan sulfate binding site (PDB: 1GMN).

HES1 protein expression was significantly up-regulated $(\mathrm{P}<0.05)$ at day 21 following $\beta$-GP treatment (Fig. 4C) which was significantly downregulated after C2 and DAPT treatment $(\mathrm{P}<0.001)$, whereas $\mathrm{C} 4$ and crizotinib exerted a non-significant effect. When compared with the untreated control VSMCs, DAPT significantly $(\mathrm{P}<0.01)$ decreased HES1 protein expression (Fig. 4C).

\section{Glycomimetic modulation of the H/HS interaction with HGF}

Based on the downstream knockdown of c-Met phosphorylation with glycomimetics $\mathrm{C} 2$ and $\mathrm{C} 4$ in an analogous manner to the known c-Met inhibitor, Crizotinib [35], possible binding modes for $\mathrm{C} 2$ and $\mathrm{C} 4$ upstream of c-Met were proposed. The c-Met receptor has both an intracellular kinase domain and an extracellular receptor binding domain as two potential binding sites [36]. Based on the polar nature of C2 and C4 and lack of hinge-binding motifs, it is highly unlikely that they cross the membrane but instead act at the extracellular receptor level rather than directly with the kinase domain. HGF is a known c-Met receptor agonist and NK4 a known c-Met receptor antagonist [18]. Whether the glycomimetic interacts directly with HGF and prevents binding or acts as a receptor antagonist (like NK4) remains to be elucidated. However, it would be unlikely for a simple small molecule to mimic a larger protein surface so effectively. In order to predict the binding possibilities of C2 and C4 to HGF, the docking program GOLD $[37,38]$ was used to generate the lowest energy binding poses, shown in Fig. 5. Both these binding poses, mimic the region that the known HGFbinder, heparan sulfate binds to with good confidence. It would seem most likely that $\mathrm{C} 2$ and C4 mimic the binding event of HGF-H/HS and disrupt HGF from engaging with c-Met and activating downstream c-Met phosphorylation.

\section{Discussion}

Vascular calcification is a highly regulated process of reprogramming VSMC into osteo-/ chondrogenic phenotypes $[39,40]$ provoked by increased extracellular phosphate [41], but also induced under conditions of with inflammation (TNFa, IL6), oxidative stress elevated LDL cholesterol, aging (senescence and DNA damage) in combination with either osteoporosis, or atherosclerosis $[4,9,42]$.. Use of high phosphorus and calcium levels in cell culture media is a well established in vitro model for the study of the osteogenic differentiation of VSMCs [43]. 


\section{Cellular Physiology Cell Physiol Biochem 2019;53:323-336 \\ \begin{tabular}{ll|l} 
and Biochemistry $\begin{array}{l}\text { DOl: 10.3594/000000141 } \\
\text { Published online: } 31 \text { July 2019 }\end{array}$ & $\begin{array}{l}\text { O } 2019 \text { The Author(s). Published by } \\
\text { Cell Physiol Biochem Press GmbH\&Co. KG }\end{array}$ \\
\cline { 2 - 3 }
\end{tabular} \\ Mahmoud et al.: Glycomimetics Prevent Vascular Calcification}

Indeed, increased serum levels of inorganic phosphate are believed to link bone turnover to vascular calcification and play a significant role in the development of VSMC calcification [44, 45]. This role has been supported by studies where reducing hyperphosphatemia through treatment with phosphate-binding agents effectively prevented vascular calcification in mice [46] and chronic kidney disease patients [47].

In the present study, $\beta$-GP induced calcification of the human VSMCs, demonstrated by positive alizarin red staining and calcium deposition. It is well-known that $\beta$-GP releases inorganic phosphate and raises its concentration in the culture medium [33], therefore, this model was chosen for our investigation. Calcium deposition was assayed at day 14 and the findings were similar to those reported by Alesutan et al. in primary human aortic smooth muscle cells at the same time point, suggesting similarities between different vascular beds [48].

Interestingly, all 4 small molecule glycomimetics used in this study markedly inhibited $\beta$-GP-induced calcium deposition and VSMC calcification. The four glycomimetics are highly charged polar molecules with 3-4 sulfate groups and therefore, will have similar physicochemical properties. Furthermore, the molecular modelling demonstrates the similarity of interaction for the two key structures and may explain the similarity of activity demonstrated. Since $\beta$-GP induces calcification in an ALP-dependent manner [49], we assayed the effect of C1-C4 HS mimetics on both activity and gene expression of ALP. All small molecule glycomimetics inhibited the $\beta$-GP-induced increase in ALP activity at days 4,7 and 10 , and ALP mRNA abundance at day 7. Since increased activity of ALP is an early marker of calcification, our findings support a potential role for small molecule glycomimetics in attenuation of VSMC mineralisation/calcification.

In the knowledge that vascular calcification is a complex process due to an elevated calcium phosphate product, and is known to involve an active transdifferentiation into osteoblast-like cells [50], the effect of C1-C4 glycomimetics on the expression of specific genes in osteoblastic and osteogenic cells were investigated. Multiple studies have demonstrated increased expression of osteoblastic and calcification markers such as BMP-2, Runx2, ALP and OPN in calcified valves and vessels $[39,51]$. These findings were supported by in vitro studies showing up-regulated $B M P-2, R U N X 2, A L P$ and $O P N$ in VSMCs subjected to elevated phosphate levels $[48,52,53]$. We hypothesized that down-regulating expression of these osteoblastic and calcification markers by the test glycomimetics mediate, at least in part, $\beta$-GP-induced vascular calcification. Here, $\beta$-GP-treated VSMCs exhibited a substantial increase in the mRNA abundance of BMP-2, RUNX2, MSX2 and OPN, an effect that was markedly prevented by $\mathrm{C} 1-\mathrm{C} 4$ glycomimetics.

BMP-2 is a crucial factor in the regulation of osteogenic differentiation and osteoblast proliferation. Like osteoblasts, VSMCs are derived from the mesenchymal precursor cells which can express and secrete BMP-2 [54] and has been implicated in promoting calcification of VSMCs in humans [7, 55, 56]. Pathological studies of calcified vessels have shown increased expression of BMP-2 and several downstream bone-related proteins [57, 58]. A recent study by Sun et al. reported the role of endogenous BMP- 2 and osteogenic differentiation in the process of vascular calcification [59]. BMP-2 accelerates phosphate uptake [7], and upregulates expression of Runx2 [9] and ALP [10]. Runx2 is an osteogenic transcription factor involved in the differentiation of osteo-/chondrogenic phenotype [60] and studies have demonstrated that Runx2 orchestrates the transformation of VSMC into osteoblast-like cells $[61,62]$ through regulating several dependent genes including ALP, OPN and other factors $[63,64]$. Runx2 increases the expression of receptor activator of nuclear factor $\kappa B$ ligand (RANKL) leading to transdifferentiation of SMCs into osteoblast-like cells [65]. Elevated levels of extracellular phosphate have been reported to induce Runx2 and other osteoblastic differentiation factors [48].

In addition, BMP-2 induces Msx2 expression leading to osteogenic differentiation and mineralisation of VSMCs [54]. Msx2 is a homeodomain transcription factor that commits mesenchymal cells to osteogenesis, not to adipogenesis [66] and is responsible for differentiation and mineralisation of osteoblasts [67]. Experiments using a mouse model 
Fig. 6. Schematic diagram demonstrating the protective effects of small molecule glycomimetics against phosphateinduced osteogenic signalling and vascular calcification.

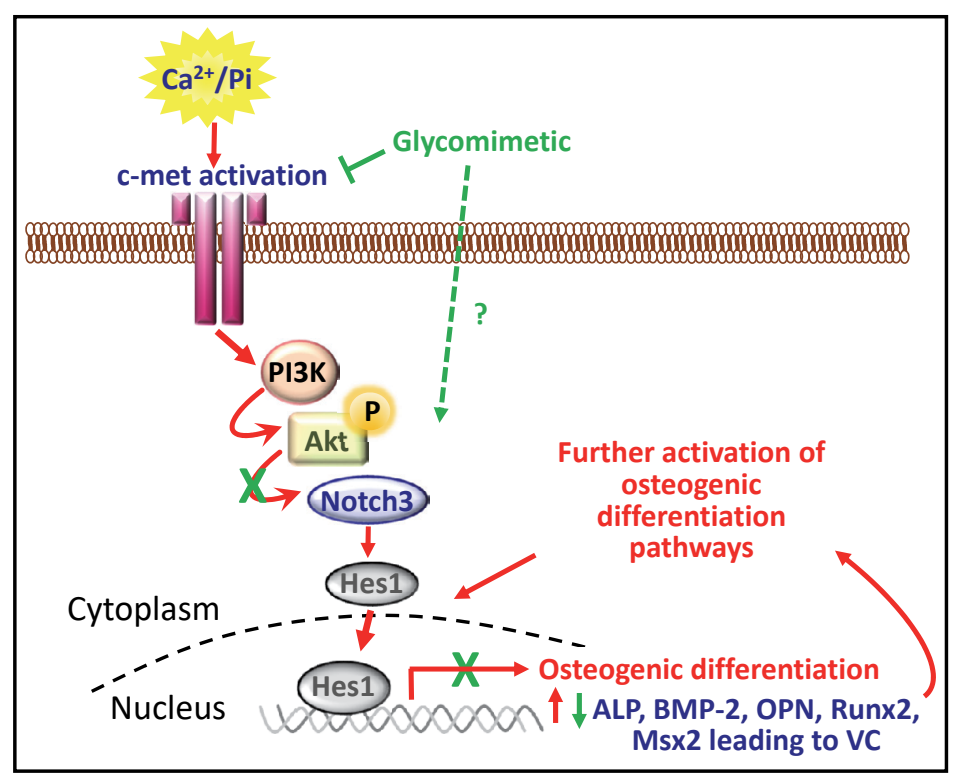

of medial artery calcification showed activated gene expression of BMP-2 and Msx2 in the aortic adventitia $[68,69]$. We and others $[70,71]$ have shown that Msx2 mediates the Notch signalling-induced osteogenic differentiation of VSMCs. Shimizu et al. also reported a crosstalk between Notch and BMP-2 signalling in VSMCs, leading to enhanced activation of Msx2 during vascular calcification [54]. Notch was also demonstrated to induce ALP activity in human aortic SMCs [70]. Hence, BMP-2 requires Notch signalling and the Notch/BMP-2induced Msx2 activation plays a role in VSMC calcification [54]. Therefore, modulation of BMP-2, Runx2 and Msx2 expression by small molecule glycomimetics in this study could represent a novel therapeutic direction for preventing vascular calcification.

Our previous work [18] revealed the role of c-Met/Akt/Notch3 signalling in the osteogenic differentiation of VSMCs, triggered by HGF. Therefore, we have investigated the possible involvement of c-Met/Notch3/HES1 in the protective role of small molecule glycomimetics against $\beta$-GP-induced vascular calcification. Notably, c-Met phosphorylation and HES1 protein expression were significantly increased in VSMCs treated with $\beta$-GP at day 21, which were significantly decreased by the glycomimetics. HES1 has been reported to stimulate Runx2 activity and osteogenesis [42]. The small molecule glycomimetics inhibited c-Met phosphorylation, and Notch3 and HES1 expression, suggesting that the c-Met/ Notch3/HES1 signalling pathway could play a role in their protective effect against VSMC calcification. Due to the highly polar nature of the glycomimetics, designed to mimic the HGFheparan sulfate binding interaction [31], an extracellular modulation of the ability of HGF to bind to c-Met has been proposed.

\section{Conclusion}

In summary, this is the first study demonstrating that these small molecule glycomimetics can attenuate VSMC calcification through decreasing calcium deposition, down-regulation of osteoblastic and calcification markers, and modulation of the c-Met/Notch3/HES1 signalling pathway (Fig. 6). However, further studies are required to better understand the role of c-Met/Notch3/HES1 signalling in mediating the protective effect of these glycomimetics against VSMC calcification. Our study may serve as a base for the development of a new drug for vascular calcification, for potential translation to the clinic. 


\section{Cellular Physiology Cell Physiol Biochem 2019;53:323-336

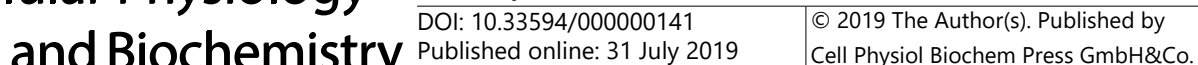 \\ Mahmoud et al.: Glycomimetics Prevent Vascular Calcification}

\section{Acknowledgements}

The authors wish to thank the Science \& Technology Development Fund (STDF; EGYPT), the International Atherosclerosis Society (IAS; USA) for supporting the travel of Ayman Mahmoud and The British Heart Foundation for funding this work (PG/14/30/30784 to MYA and FLW). The authors also thank Cambridge Crystallographic Data Centre (CCDC) for a demonstrational loan of GOLD 5.4.1 and HERMES 1.8.1 software.

Author contributions: A.M.M., M.Y.A. and F.L.W. conceived the study, designed the experiments and wrote the paper. A.M.M. carried out all experiments and performed the statistical analyses. A.M.J. generated the glycomimetics and performed the GOLD analysis. A.M.A. and G.S. participated in the critical manuscript revision. All authors read and approved the final manuscript.

\section{Disclosure Statement}

The authors have no conflicts of interest to declare.

\section{References}

1 Leem J, Lee IK: Mechanisms of Vascular Calcification: The Pivotal Role of Pyruvate Dehydrogenase Kinase 4. Endocrinol Metab (Seoul) 2016;31:52-61.

2 Schurgin S, Rich S, Mazzone T: Increased prevalence of significant coronary artery calcification in patients with diabetes. Diabetes Care 2001;24:335-338.

3 Pundziute G, Schuijf JD, Jukema JW, van Werkhoven JM, Nucifora G, Decramer I, Sarno G, Vanhoenacker PK, Reiber JH, Wijns W, Bax JJ: Type 2 diabetes is associated with more advanced coronary atherosclerosis on multislice computed tomography and virtual histology intravascular ultrasound. J Nucl Cardiol 2009;16:376-383.

4 Otsuka F, Sakakura K, Yahagi K, Joner M, Virmani R: Has our understanding of calcification in human coronary atherosclerosis progressed? Arterioscler Thromb Vasc Biol 2014;34:724-736.

5 Ndip A, Wilkinson FL, Jude EB, Boulton AJ, Alexander MY: RANKL-OPG and RAGE modulation in vascular calcification and diabetes: novel targets for therapy. Diabetologia 2014;57:2251-2260.

6 Wilkinson FL, Liu Y, Rucka AK, Jeziorska M, Hoyland JA, Heagerty AM, Canfield AE, Alexander MY: Contribution of VCAF-positive cells to neovascularization and calcification in atherosclerotic plaque development. J Pathol 2007;211:362-369.

7 Li X, Yang HY, Giachelli CM: BMP-2 promotes phosphate uptake, phenotypic modulation, and calcification of human vascular smooth muscle cells. Atherosclerosis 2008;199:271-277.

8 Miyazono K, Kusanagi K, Inoue H: Divergence and convergence of TGF-beta/BMP signaling. J Cell Physiol 2001;187:265-276.

9 Shao JS, Aly ZA, Lai CF, Cheng SL, Cai J, Huang E, Behrmann A, Towler DA: Vascular Bmp Msx2 Wnt signaling and oxidative stress in arterial calcification. Ann N Y Acad Sci 2007;1117:40-50.

10 Rawadi G, Vayssiere B, Dunn F, Baron R, Roman-Roman S: BMP-2 controls alkaline phosphatase expression and osteoblast mineralization by a Wnt autocrine loop. J Bone Miner Res 2003;18:1842-1853.

11 Zamurovic N, Cappellen D, Rohner D, Susa M: Coordinated activation of notch, Wnt, and transforming growth factor-beta signaling pathways in bone morphogenic protein 2-induced osteogenesis. Notch target gene Hey1 inhibits mineralization and Runx2 transcriptional activity. J Biol Chem 2004;279:37704-37715.

12 Tsuji K, Komori T, Noda M: Aged mice require full transcription factor, Runx2/Cbfa1, gene dosage for cancellous bone regeneration after bone marrow ablation. J Bone Miner Res 2004;19:1481-1489.

13 Chen H, Ghori-Javed FY, Rashid H, Serra R, Gutierrez SE, Javed A: Chondrocyte-specific regulatory activity of Runx2 is essential for survival and skeletal development. Cells Tissues Organs 2011;194:161-165.

14 Chen W, Ma J, Zhu G, Jules J, Wu M, McConnell M, Tian F, Paulson C, Zhou X, Wang L, Li YP: Cbfbeta deletion in mice recapitulates cleidocranial dysplasia and reveals multiple functions of Cbfbeta required for skeletal development. Proc Natl Acad Sci U S A 2014;111:8482-8487. 


\section{Cellular Physiology Cell Physiol Biochem 2019;53:323-336 \begin{tabular}{l|l|l|}
\hline DOI: 10.33594/000000141 & (O) 2019 The Author(s). Published by \\
\hline
\end{tabular} and Biochemistry Published online: 31 July 2019 Cell Physiol Biochem Press GmbH\&Co. KG \\ Mahmoud et al.: Glycomimetics Prevent Vascular Calcification}

15 Speer MY, Li X, Hiremath PG, Giachelli CM: Runx2/Cbfa1, but not loss of myocardin, is required for smooth muscle cell lineage reprogramming toward osteochondrogenesis. J Cell Biochem 2010;110:935-947.

16 Aikawa E, Nahrendorf M, Sosnovik D, Lok VM, Jaffer FA, Aikawa M, Weissleder R: Multimodality molecular imaging identifies proteolytic and osteogenic activities in early aortic valve disease. Circulation 2007;115:377-386.

17 Speer MY, Yang HY, Brabb T, Leaf E, Look A, Lin WL, Frutkin A, Dichek D, Giachelli CM: Smooth muscle cells give rise to osteochondrogenic precursors and chondrocytes in calcifying arteries. Circ Res 2009;104:733741.

18 Liu X, Wang Q, Yang G, Marando C, Koblish HK, Hall LM, Fridman JS, Behshad E, Wynn R, Li Y, Boer J, Diamond S, He C, Xu M, Zhuo J, Yao W, Newton RC, Scherle PA: A novel kinase inhibitor, INCB28060, blocks c-MET-dependent signaling, neoplastic activities, and cross-talk with EGFR and HER-3. Clin Cancer Res 2011;17:7127-7138.

19 Satani K, Konya H, Hamaguchi T, Umehara A, Katsuno T, Ishikawa T, Kohri K, Hasegawa Y, Suehiro A, Kakishita E, Namba M: Clinical significance of circulating hepatocyte growth factor, a new risk marker of carotid atherosclerosis in patients with Type 2 diabetes. Diabet Med 2006;23:617-622.

20 Liu Y, Wilkinson FL, Kirton JP, Jeziorska M, Iizasa H, Sai Y, Nakashima E, Heagerty AM, Canfield AE, Alexander MY: Hepatocyte growth factor and c-Met expression in pericytes: implications for atherosclerotic plaque development. J Pathol 2007;212:12-19.

21 Hossain M, Irwin R, Baumann MJ, McCabe LR: Hepatocyte growth factor (HGF) adsorption kinetics and enhancement of osteoblast differentiation on hydroxyapatite surfaces. Biomaterials 2005;26:2595-2602.

22 Andersson ER, Sandberg R, Lendahl U: Notch signaling: simplicity in design, versatility in function. Development 2011;138:3593-3612.

23 Baeten JT, Lilly B: Differential Regulation of NOTCH2 and NOTCH3 Contribute to Their Unique Functions in Vascular Smooth Muscle Cells. J Biol Chem 2015;290:16226-16237.

24 Sasisekharan R, Shriver Z, Venkataraman G, Narayanasami U: Roles of heparan-sulphate glycosaminoglycans in cancer. Nat Rev Cancer 2002;2:521-528.

25 Wegrowski Y, Maquart FX: Involvement of stromal proteoglycans in tumour progression. Crit Rev Oncol Hematol 2004;49:259-268.

26 Simon Davis DA, Parish CR: Heparan sulfate: a ubiquitous glycosaminoglycan with multiple roles in immunity. Front Immunol 2013;4:470.

27 Bishop JR, Schuksz M, Esko JD: Heparan sulphate proteoglycans fine-tune mammalian physiology. Nature 2007;446:1030-1037.

28 Magnani JL, Ernst B: Glycomimetic drugs--a new source of therapeutic opportunities. Discov Med 2009;8:247-252.

29 Tyler PC, Guimond SE, Turnbull JE, Zubkova OV: Single-entity heparan sulfate glycomimetic clusters for therapeutic applications. Angew Chem Int Ed Engl 2015;54:2718-2723.

30 Raiber EA, Wilkinson JA, Manetti F, Botta M, Deakin J, Gallagher J, Lyon M, Ducki SW: Novel heparin/ heparan sulfate mimics as inhibitors of HGF/SF-induced MET activation. Bioorg Med Chem Lett 2007;17:6321-6325.

31 Mahmoud AM, Wilkinson FL, Jones AM, Wilkinson JA, Romero M, Duarte J, Alexander MY: A novel role for small molecule glycomimetics in the protection against lipid-induced endothelial dysfunction: Involvement of Akt/eNOS and Nrf2/ARE signaling. Biochim Biophys Acta 2017;1861:3311-3322.

32 Ndip A, Williams A, Jude EB, Serracino-Inglott F, Richardson S, Smyth JV, Boulton AJ, Alexander MY: The RANKL/RANK/OPG signaling pathway mediates medial arterial calcification in diabetic Charcot neuroarthropathy. Diabetes 2011;60:2187-2196.

33 Shioi A, Nishizawa Y, Jono S, Koyama H, Hosoi M, Morii H: Beta-glycerophosphate accelerates calcification in cultured bovine vascular smooth muscle cells. Arterioscler Thromb Vasc Biol 1995;15:2003-2009.

34 Kirton JP, Wilkinson FL, Canfield AE, Alexander MY: Dexamethasone downregulates calcification-inhibitor molecules and accelerates osteogenic differentiation of vascular pericytes: implications for vascular calcification. Circ Res 2006;98:1264-1272.

35 Christensen JG, Zou HY, Arango ME, Li Q, Lee JH, McDonnell SR, Yamazaki S, Alton GR, Mroczkowski B, Los G: Cytoreductive antitumor activity of PF-2341066, a novel inhibitor of anaplastic lymphoma kinase and c-Met, in experimental models of anaplastic large-cell lymphoma. Mol Cancer Ther 2007;6:3314-3322.

36 Organ SL, Tsao MS: An overview of the c-MET signaling pathway. Ther Adv Med Oncol 2011;3:S7-S19. 


\section{Cellular Physiology Cell Physiol Biochem 2019;53:323-336 \begin{tabular}{l|l|l|}
\hline DOI: 10.33594/000000141 & ( 2019 The Author(s). Published by \\
\hline
\end{tabular} and Biochemistry Published online: 31 July 2019 Cell Physiol Biochem Press GmbH\&Co. KG \\ Mahmoud et al.: Glycomimetics Prevent Vascular Calcification}

37 Jones G, Willett P, Glen RC: Molecular recognition of receptor sites using a genetic algorithm with a description of desolvation. J Mol Biol 1995;245:43-53.

38 Jones G, Willett P, Glen RC, Leach AR, Taylor R: Development and validation of a genetic algorithm for flexible docking. J Mol Biol 1997;267:727-748.

39 Steitz SA, Speer MY, Curinga G, Yang HY, Haynes P, Aebersold R, Schinke T, Karsenty G, Giachelli CM: Smooth muscle cell phenotypic transition associated with calcification: upregulation of $\mathrm{Cbfa} 1$ and downregulation of smooth muscle lineage markers. Circ Res 2001;89:1147-1154.

40 Mizobuchi M, Towler D, Slatopolsky E: Vascular calcification: the killer of patients with chronic kidney disease. J Am Soc Nephrol 2009;20:1453-1464.

41 Giachelli CM: Vascular calcification: in vitro evidence for the role of inorganic phosphate. J Am Soc Nephrol 2003;14:S300-S304.

42 Zayzafoon M, Abdulkadir SA, McDonald JM: Notch signaling and ERK activation are important for the osteomimetic properties of prostate cancer bone metastatic cell lines. J Biol Chem 2004;279:3662-3670.

43 Davies MR, Lund RJ, Mathew S, Hruska KA: Low turnover osteodystrophy and vascular calcification are amenable to skeletal anabolism in an animal model of chronic kidney disease and the metabolic syndrome. J Am Soc Nephrol 2005;16:917-928.

44 Moe SM, Chen NX: Pathophysiology of vascular calcification in chronic kidney disease. Circ Res 2004;95:560-567.

45 Li X, Yang HY, Giachelli CM: Role of the sodium-dependent phosphate cotransporter, Pit-1, in vascular smooth muscle cell calcification. Circ Res 2006;98:905-912.

46 Mathew S, Lund RJ, Strebeck F, Tustison KS, Geurs T, Hruska KA: Reversal of the adynamic bone disorder and decreased vascular calcification in chronic kidney disease by sevelamer carbonate therapy. J Am Soc Nephrol 2007;18:122-130.

47 Koizumi M, Fukagawa M: [Treatment of hyperphosphatemia with sevelamer hydrochloride in CKD patients: effects on vascular calcification and mortality]. Clin Calcium 2010;20:1700-1708.

48 Alesutan I, Musculus K, Castor T, Alzoubi K, Voelkl J, Lang F: Inhibition of Phosphate-Induced Vascular Smooth Muscle Cell Osteo-/Chondrogenic Signaling and Calcification by Bafilomycin A1 and Methylamine. Kidney Blood Press Res 2015;40:490-499.

49 Proudfoot D, Skepper JN, Hegyi L, Bennett MR, Shanahan CM, Weissberg PL: Apoptosis regulates human vascular calcification in vitro: evidence for initiation of vascular calcification by apoptotic bodies. Circ Res 2000;87:1055-1062.

50 Reynolds JL, Joannides AJ, Skepper JN, McNair R, Schurgers LJ, Proudfoot D, Jahnen-Dechent W, Weissberg PL, Shanahan CM: Human vascular smooth muscle cells undergo vesicle-mediated calcification in response to changes in extracellular calcium and phosphate concentrations: a potential mechanism for accelerated vascular calcification in ESRD. J Am Soc Nephrol 2004;15:2857-2867.

51 Shanahan CM, Cary NR, Salisbury JR, Proudfoot D, Weissberg PL, Edmonds ME: Medial localization of mineralization-regulating proteins in association with Monckeberg's sclerosis: evidence for smooth muscle cell-mediated vascular calcification. Circulation 1999;100:2168-2176.

52 Lee KM, Kang HA, Park M, Lee HY, Choi HR, Yun CH, Oh JW, Kang HS: Interleukin-24 attenuates betaglycerophosphate-induced calcification of vascular smooth muscle cells by inhibiting apoptosis, the expression of calcification and osteoblastic markers, and the Wnt/beta-catenin pathway. Biochem Biophys Res Commun 2012;428:50-55.

53 Montes de Oca A, Guerrero F, Martinez-Moreno JM, Madueno JA, Herencia C, Peralta A, Almaden Y, Lopez I, Aguilera-Tejero E, Gundlach K, Buchel J, Peter ME, Passlick-Deetjen J, Rodriguez M, Munoz-Castaneda JR: Magnesium inhibits Wnt/beta-catenin activity and reverses the osteogenic transformation of vascular smooth muscle cells. PLoS One 2014;9:e89525.

54 Shimizu T, Tanaka T, Iso T, Matsui H, Ooyama Y, Kawai-Kowase K, Arai M, Kurabayashi M: Notch signaling pathway enhances bone morphogenetic protein 2 (BMP2) responsiveness of Msx2 gene to induce osteogenic differentiation and mineralization of vascular smooth muscle cells. J Biol Chem 2011;286:19138-19148.

55 Willette RN, Gu JL, Lysko PG, Anderson KM, Minehart H, Yue T: BMP-2 gene expression and effects on human vascular smooth muscle cells. J Vasc Res 1999;36:120-125.

56 Yan JY, Zhou Q, Yu HM, Hou ML, Lu LH: High glucose promotes vascular smooth muscle cell calcification by activating WNT signaling pathway. Nan Fang Yi Ke Da Xue Xue Bao 2015;35:29-33. 


\section{Cellular Physiology Cell Physiol Biochem 2019;53:323-336 \begin{tabular}{c|c|c|} 
DOl: $10.33594 / 000000141$ & () 2019 The Author(s). Published by \\
and Biochemistry Published online: 31 July 2019 & Cell Physiol Biochem Press GmbH\&Co
\end{tabular} \\ Mahmoud et al.: Glycomimetics Prevent Vascular Calcification}

57 Zhu D, Mackenzie NC, Millan JL, Farquharson C, MacRae VE: The appearance and modulation of osteocyte marker expression during calcification of vascular smooth muscle cells. PLoS One 2011;6:e19595.

58 Kim JH, Choi YK, Do JY, Ha CM, Lee SJ, Jeon JH, Lee WK, Choi HS, Park KG, Lee IK: Estrogen-Related Receptor gamma Plays a Key Role in Vascular Calcification Through the Upregulation of BMP2 Expression. Arterioscler Thromb Vasc Biol 2015;35:2384-2390.

59 Sun Y, Byon CH, Yuan K, Chen J, Mao X, Heath JM, Javed A, Zhang K, Anderson PG, Chen Y: Smooth muscle cell-specific runx2 deficiency inhibits vascular calcification. Circ Res 2012;111:543-552.

60 Dalle Carbonare L, Innamorati G, Valenti MT: Transcription factor Runx2 and its application to bone tissue engineering. Stem Cell Rev 2012;8:891-897.

61 Kuro-o M: Klotho, phosphate and FGF-23 in ageing and disturbed mineral metabolism. Nat Rev Nephrol 2013;9:650-660.

62 Lin ME, Chen T, Leaf EM, Speer MY, Giachelli CM: Runx2 Expression in Smooth Muscle Cells Is Required for Arterial Medial Calcification in Mice. Am J Pathol 2015;185:1958-1969.

63 Weng JJ, Su Y: Nuclear matrix-targeting of the osteogenic factor Runx2 is essential for its recognition and activation of the alkaline phosphatase gene. Biochim Biophys Acta 2013;1830:2839-2852.

64 Lau WL, Festing MH, Giachelli CM: Phosphate and vascular calcification: Emerging role of the sodiumdependent phosphate co-transporter PiT-1. Thromb Haemost 2010;104:464-470.

65 Byon CH, Sun Y, Chen J, Yuan K, Mao X, Heath JM, Anderson PG, Tintut Y, Demer LL, Wang D, Chen Y: Runx2upregulated receptor activator of nuclear factor kappaB ligand in calcifying smooth muscle cells promotes migration and osteoclastic differentiation of macrophages. Arterioscler Thromb Vasc Biol 2011;31:13871396.

66 Cheng SL, Shao JS, Charlton-Kachigian N, Loewy AP, Towler DA: MSX2 promotes osteogenesis and suppresses adipogenic differentiation of multipotent mesenchymal progenitors. J Biol Chem 2003;278:45969-45977.

67 Wilkie AO, Tang Z, Elanko N, Walsh S, Twigg SR, Hurst JA, Wall SA, Chrzanowska KH, Maxson RE, Jr.: Functional haploinsufficiency of the human homeobox gene MSX2 causes defects in skull ossification. Nat Genet 2000;24:387-390.

68 Towler DA, Bidder M, Latifi T, Coleman T, Semenkovich CF: Diet-induced diabetes activates an osteogenic gene regulatory program in the aortas of low density lipoprotein receptor-deficient mice. J Biol Chem 1998;273:30427-30434.

69 Shao JS, Cheng SL, Pingsterhaus JM, Charlton-Kachigian N, Loewy AP, Towler DA: Msx2 promotes cardiovascular calcification by activating paracrine Wnt signals. J Clin Invest 2005;115:1210-1220.

70 Shimizu T, Tanaka T, Iso T, Doi H, Sato H, Kawai-Kowase K, Arai M, Kurabayashi M: Notch signaling induces osteogenic differentiation and mineralization of vascular smooth muscle cells: role of Msx2 gene induction via Notch-RBP-Jk signaling. Arterioscler Thromb Vasc Biol 2009;29:1104-1111.

71 Yan J, Stringer SE, Hamilton A, Charlton-Menys V, Gotting C, Muller B, Aeschlimann D, Alexander MY: Decorin GAG synthesis and TGF-beta signaling mediate Ox-LDL-induced mineralization of human vascular smooth muscle cells. Arterioscler Thromb Vasc Biol 2011;31:608-615. 